\title{
A MANIPULAÇÃO DA VIDA AFETIVA DOS GRUPOS: O CASO DOS TRABALHADORES EM UMA LOJA DE DEPARTAMENTOS
}

\author{
Francis Kanashiro Meneghetti ${ }^{1}$ \\ Édna Regina Cicmanec ${ }^{2}$
}

\section{Resumo}

O estudo de caso aqui proposto tem como objetivo analisar como ocorre a manipulação da vida afetiva de um grupo de trabalhadores de uma loja de departamentos submetidos a uma dinâmica de grupo (reunião) realizada cotidianamente na Organização R. O nível de análise é organizacional e a unidade de análise o grupo de funcionários da loja de departamentos. Conclui-se que a Organização $\mathrm{R}$ adota práticas de espetacularização para disseminar sua ideologia e usa das lideranças para ampliar seu domínio sobre os aspectos subjetivos dos trabalhadores. Além disso, a organização explora dinâmicas lúdicas (música, dança e brincadeiras infantis) para manipular a vida afetiva do grupo e fazer com que os indivíduos aceitem metas e objetivos definidos pela organização.

Palavras-chave: Espetacularização; Ideologia; Manipulação.

\section{THE MANIPULATION OF THE AFFECTIVE LIFE OF GROUPS: THE CASE} OF EMPLOYEES OF A DEPARTMENT STORE

\begin{abstract}
The case study proposed here aims to analyze how does the manipulation of the emotional life of a group of workers from a store departments submitted to a group dynamic ( meeting) held daily in R Organization. The level of analysis is organizational and unit of analysis the group of employees of the department store. It is concluded that the R Organization adopts spectacle practices to spread their ideology and uses of leaders to extend their hold on the subjective aspects of workers. In addition, the organization explores recreational dynamics (music, dance and children's

\footnotetext{
${ }^{1}$ Professor EBTT do Departamento Acadêmico de Gestão e Economia e do Programa de Pós-Graduação (Mestrado e Doutorado) em Tecnologia da Universidade Tecnológica Federal do Paraná (UTFPR). E-mail: fkmeneghetti@gmail.com

2 Doutora e Mestre em Administração pela Universidade Positivo. Docente nas áreas de Administração e Marketing na FAE - Centro Universitário. E-mail: ednacicmanec@gmail.com
} 
A MANIPULAÇÃO DA VIDA AFETIVA DOS GRUPOS:

play ) to handle the emotional life of the group and cause individuals to accept goals and objectives set by the organization .

Keywords: Spectacularization; Ideology ; Manipulation.

\section{Introdução}

As obras de Pagès $(1968,1992)$ e de Enriquez $(1982,1989,1992)$ são importantes referências para compreender a forma como as organizações investem em formas cada vez mais sofisticadas de controle no trabalho. Autores brasileiros como Motta e Freitas (2000) e Faria (2007) também discorrem sobre as formas como as organizações implementam estratégias e formas cada vez mais rebuscadas de controles, diretos e indiretos, sobre os trabalhadores. As organizações investem tanto no controle direto do trabalhador, como em métodos cada vez mais sofisticados, onde o próprio trabalhador internaliza as regras e normas por meio do autocontrole de suas ações. O estudo de Faria e Meneghetti (2007) mostra como a organização é capaz de sequestrar a subjetividade do trabalhador no sistema toyotista de produção a partir de uma forma específica de organização produtiva e de técnicas de gestão baseadas no colaboracionismo, no trabalho em equipe e na ajuda mútua e permanente entre os trabalhadores.

As organizações precisam permanentemente renovar seu repertório de técnicas gerenciais para obter cada vez mais produtividade. Por isto, as organizações investem cada vez mais na vida afetiva dos grupos, com a finalidade de criar condições mais favoráveis para a organização realizar seus objetivos e metas. Tentando compreender melhor como as organizações buscam novas formas de controle sobre o trabalhador, o objetivo geral deste trabalho é analisar como ocorre a manipulação da vida afetiva de um grupo de trabalhadores de uma loja de departamentos submetidos a uma situação de dinâmica de grupo (reunião diária) realizada cotidianamente na Organização $R$.

Os objetivos específicos são: (i) Analisar como se caracteriza as práticas de espetacularização e disseminação ideológica na Organização R.; (ii) Avaliar como se manifestam as emoções e os sentimentos nas reuniões diárias realizadas no grupo de trabalho; (iii) Analisar como se caracterizam os vínculos no grupo, as ilusões grupais e o processo de identificação no grupo; por fim, (iv) Refletir sobre as consequências da manipulação vida afetiva do grupo pesquisado.

Por questões didáticas, este artigo está dividido em introdução, metodologia, fundamentação teórica, análise dos dados e considerações finais. Na introdução apresenta-se o contexto do trabalho e os objetivos geral e específicos. Na metodologia são apresentadas as especificidades 
A MANIPULAÇÃO DA VIDA AFETIVA DOS GRUPOS:

metodológicas e as justificativas para suas utilizações. Na fundamentação teórica são discutidos os conceitos e categorias centrais para posterior análise deles. $\mathrm{Na}$ análise dos dados, o caso apresentado, apesar de ser único, está dividido em situações de 1 a 6 . As situações estão na sequência original do registro fílmico. Eles foram didaticamente divididos para facilitar nas análises e a exposição dos resultados. Por fim, as considerações finais procuram responder os objetivos propostos.

\section{Espetacularização e Disseminação Ideológica nas Organizações Modernas}

As organizações eram vistas como sistemas produtivos objetivos. $\mathrm{O}$ lugar da produção onde os indivíduos trabalhavam em troca de recompensas econômicas. Imperava uma visão racional da organização. A visão de Taylor de organização como máquina era a visão dominante. Após algum tempo uma nova abordagem ganhou destaque: a que entende a organização como um sistema cultural, simbólico e imaginário (ENRIQUEZ, 1992), lugar onde se manifestam imaginários, fantasmas, desejos individuais e coletivos, projetos conscientes e inconscientes.

$\mathrm{Na}$ atualidade, as organizações investem sobre a vida afetiva dos indivíduos que compõem os grupos dentro delas. Por isto, investem na "gestão" da vida afetiva, do imaginário coletivo, das subjetividades dos indivíduos, originários do inconsciente individual e coletivo da organização.

Os resultados esperados pela organização passa pela gestão da felicidade dos indivíduos, pela gestão dos aspectos mais subjetivos e íntimos de cada trabalhador. Buscam-se formas cada vez mais sofisticadas de captura da intimidade de cada um. Assim, as organizações (principalmente as empresas produtivas modernas), investem na criação de uma teia imaginária para "controlar" a psique dos indivíduos (ENRIQUEZ, 1989).

Enriquez (1989) afirma que a forma mais eficiente de "controlar", mesmo que parcialmente, a psique dos indivíduos é investindo em um imaginário baseado na aparência de democracia, de colaboracionismo, de cooperativismo. Tais valores rebatem aparentemente $\mathrm{o}$ ambiente burocrático e tecnocrático das organizações modernas.

Para investir neste imaginário, a organização procura "administrar" os grupos, local adequado para a o "controle" dos aspectos mais íntimos dos trabalhadores. O primeiro princípio para o aparecimento do grupo é a existência de um projeto comum. Um grupo só se institui quando há um projeto em que todos participam e acreditam. Para manter sua permanência, um grupo necessita de regras e da existência de interdições, frequentemente representadas pelas lideranças. Os grupos tendem a instabilidade também, porque neles há a presença de sentimentos 
ambivalentes e imaginários contraditórios. Assim, nos grupos manifestam-se sentimentos como amor, ódio, solidariedade, veneração, amizade, perversões, etc. Os grupos têm ainda a capacidade se imaginar, de ter uma visão de si mesmo. (CASTORIADIS, 1975). Na dinâmica do grupo, os indivíduos alienam-se da percepção de si mesmo e passam a perceber o grupo como elemento principal.

Sabendo disto, as organizações investem na produção de uma ideologia capaz de estabelecer controle sobre os indivíduos, por meio dos grupos os quais pertencem. A produção da ideologia mascara, desloca e desvia as práticas autoritárias e perversas nas organizações. Quando os indivíduos são convidados a produzir a ideologia dentro da organização, eles se tornam os articuladores da banalização da injustiça social (DEJOURS, 2000). A ideologia, desta forma, é um instrumento permanente de poder. Os produtores da ideologia articulam o simbólico instituindo a violência simbólica. Ao mesmo tempo em que produzem são suas vítimas. Sendo assim, há uma prática da vítima de si mesmo, orientada pelos valores e crenças que a organização tenta de forma contundente instituir.

Segundo Enriquez (1983), não existe capitalismo sem que os capitalistas sejam minimamente inteligentes e estabeleçam uma forma de exploração. Mas não existe capitalismo sem pessoas que aceitem e se submetam as suas formas de exploração. As formas de exploração precisam ser legitimadas a partir de um imaginário instituído (CASTORIADIS 1975).

As multinacionais são responsáveis por desenvolverem novas formas de controle sobre os indivíduos. Suas práticas são as da "violência doce", da organização hipermoderna. (PAGÈS et. al. 1992). A multinacional impõe uma religião da empresa por meio das suas políticas de recursos humanos. A ideologia da organização é incorporada pelos indivíduos, que são permanentemente convidados a reproduzi-la coletivamente. É possível identificar contradições no interior da organização. Ao mesmo tempo em que os indivíduos sentem prazer, sofrem com as formas de dominação direta e sutil. Assim, são as vilãs e as vítimas de si mesmas. (PAGÈS et al. 1992).

Segundo Pagès et al. (1992), a organização hipermoderna, em comparação à organização moderna, caracteriza-se pelo desenvolvimento de processos de mediação objetivos e intersubjetivos entre os interesses da organização e os dos indivíduos. Para conseguir o máximo desempenho dos trabalhadores, age por meio de políticas de recursos humanos que garantem recompensas objetivas (salários, planos de saúde, de previdência complementar, etc.) e intersubjetivas (reconhecimento social, satisfação em trabalhar em equipe, etc.). Por meio de atividades especificas, cria um universo imaginário para esconder a verdadeira natureza das tarefas que realizam. A rotina, as tarefas mecânicas cansativas, a pressão por resultados precisa ser mascarada por meio de 
A MANIPULAÇÃO DA VIDA AFETIVA DOS GRUPOS:

um universo simbólico criado para instituir um imaginário positivo para a organização.

As organizações modernas também aderem a espetacularização como forma de dominação e controle dos trabalhadores. Segundo Debord (2002), o espetáculo é ideologia por excelência, porque expõe e manifesta em sua plenitude a essência de todo sistema ideológico, levando ao empobrecimento, a sujeição e a negação da vida real.

A espetacularização conduz o sujeito ao paralelismo e à falsa consciência de uma vida sujeita essencialmente ao espetáculo, mediada tecnicamente pelos signos e sinais, que materializam o ideal abstrato (DEBORD, 2002). Logo, na formação do imaginário em seu ambiente, as organizações, além de contar com a influência massiva dos discursos (sob suas diversas formas), dispõem também de diversas técnicas de gestão como recursos para ampliar a alienação do trabalhador. Os discursos materializam as palavras que viabilizam a criação de modelos, regras, padrões de comportamento, diálogos e condutas aceitáveis, enfim, procede-se a uma espécie de enquadramento social, um padrão coletivo que evita situações conflituosas por meio de sua propriedade de controlar os grupos.

Os discursos, nesse aspecto, permitem ao indivíduo justificar a suspensão da vontade individual e a aceitação passiva da dominação, propiciando a consequente formação da vontade coletiva e levando, a esse indivíduo separado de si, a sensação de pertencimento e de acolhimento social. Por outro lado, para a concretização material dos discursos, os indivíduos e as organizações mergulham na encenação do espetáculo, que necessita de certo ajuste entre o dito e o figurado, a fim de autenticar a atuação individual, coletiva e organizacional. A tradição do espetáculo está implícita nos rituais antigos (de natureza antropológica), nas artes e nas recreações populares, cujos elementos mais remotos se encontram em festas, danças, ritos, cantos e representações dramáticas primitivas. Esta tradição do espetáculo ocorreu antes mesmo da formação de uma sociedade regida por leis econômicas capitalistas, sendo, portanto, uma prática que independe das formas de relação econômica que se estabelecem.

Para que a espetacularização e a disseminação ideológica da organização possa ser realizada de forma eficiente, as organizações precisam criar situações específicas para que isto ocorra. No item a seguir será discutido como se caracterizam os grupos e como sua dinâmica possibilita que os indivíduos sejam sugestionados a aceitar elementos de interesse da organização.

\section{A Vida Afetiva dos Grupos}


A MANIPULAÇÃO DA VIDA AFETIVA DOS GRUPOS:

Freud (1991) concluiu, partindo das observações de Le Bon (1991), não haver uma oposição significativa entre a psicologia individual e a psicologia social. A figura do outro está presente na vida psíquica do indivíduo, sendo na forma de exemplo, apoio ou adversário. A psicologia de grupo trata, pois, do indivíduo isolado como membro de uma casta, de uma classe, de uma linguagem, de um povo que se organizam por determinado tempo para realizar objetivos específicos.

Segundo Zimerman (1997), um grupo não é um mero somatório de indivíduos; pelo contrário, ele se constitui como uma nova entidade, com leis e mecanismos próprios e específicos. O grupo se comporta como uma totalidade e coexistem duas forças contraditórias permanentemente em jogo: uma tendente à sua coesão e a outra, à sua desintegração. Nos grupos sempre vai existe uma hierárquica distribuição de posições e de papéis, de distintas modalidades.

Não existe um grupo sem um projeto comum; um grupo só é passível de coesão quando há um projeto do qual todos participam e em que acreditam. Há a necessidade de uma instância interditora que regule o grupo e estabeleça regras para o seu funcionamento: os membros se comprometem em não ultrapassar os "limites" que foram estabelecidos, por regras formais ou imaginárias, de comum acordo entre todos. Segundo Freud (1991), todo grupo é crédulo e aberto à influência, pois não possui faculdade crítica. Pensa por imagens e os sentimentos do grupo são simples e muito exagerados. Assim, na própria dinâmica do funcionamento dos grupos e dos sentimentos pertencentes a eles, desenvolve-se um local propício para criação, manutenção e modificação do imaginário grupal, influenciado pela abertura e convivência com um mundo exterior e pela capacidade de pensar em forma de imagens.

Para um grupo tornar-se organizado, são necessárias as seguintes premissas: o grupo deve possuir certa continuidade de existência; os membros do grupo devem ter formado alguma ideia sobre o grupo, a respeito de sua natureza, composição, suas funções e capacidades; existe a interação na forma de conflito, rivalidade e sentimentos no interior do grupo. É necessário, ainda, que haja no centro dos grupos um corpo de tradições, costumes e hábitos que determinam as relações entre seus membros. Desta forma, é possível verificar que são as adversidades entre os grupos que dão o caráter dinâmico dos vínculos e dos objetivos a serem atingidos.

O grupo é um envelope capaz de fazer os indivíduos ficarem juntos, com um sistema de regras semelhante àqueles que operam em grupos religiosos; sendo assim, os grupos estariam presos em uma "trama simbólica", que é capaz de perdurar (ANZIEU, 1993, p. XVII). Nos grupos ocorrem as relações de subordinação, as coalizões e as interações ligadas aos relacionamentos com os grupos subalternos são fenômenos frequentes. 
A conduta de um grupo, portanto, deve-se à "resultante das suas forças internas e externas, às quais está submetido" (ANZIEU, 1993, p. 41-42).

No grupo deve haver certo equilíbrio entre a cobiça e as ambições individuais e a do grupo, já que o rompimento do laço coletivo pode significar a esterilidade no processo de obtenção dos resultados imaginados em cada um. Os indivíduos, como membros de um grupo, procuram não expressar seus interesses como sendo verdadeiramente seus, mas os manifestam a partir de um discurso coletivo, tentando embutir o seu desejo como sendo o desejo do grupo.

No grupo, o mecanismo de regulação é feito conforme uma análise balanceada das satisfações e insatisfações dos membros em relação aos objetivos perseguidos e pelo reajustamento periódico da condução do grupo (ANZIEU, 1993, p. 39). A dinâmica dos grupos é vivida nas representações imaginárias mais arcaicas (ANZIEU, 1993, p. 43). É no imaginário que se antecipam os conflitos e a melhor tática a ser adotada para resolvê-los; a expectativa do sucesso ou fracasso, vividos pelos grupos, é um exemplo disso. Esta situação é capaz de desencadear sentimentos que podem se concretizar na fase real das vivências grupais.

Em relação aos vínculos grupais, duas observações são significativas. O reconhecimento do desejo e o desejo de reconhecimento (identificação): o indivíduo "quer se fazer amar por si mesmo" ou pelo menos não ser rejeitado pelos demais; adquirir um prestígio é o enfoque primeiro a ser reconhecido pelo grupo. O indivíduo não apresenta seu desejo próprio, quer ser reconhecido como um membro legítimo do grupo (ENRIQUEZ, 1997, p. 95). Na medida em que cada indivíduo se assume como produtor deste imaginário, sente-se responsável por defendê-lo e reproduzi-lo. Quando o imaginário está instituído, as normas e seus valores estão fixados (ANSART, 1993). No seu interior manifestam seus desejos inconscientes. Medos, angústias, emoções diversas são manifestas no grupo. Vários membros se unem para combater o medo ou para compartilhar alegrias. Todas essas manifestações são próprias do grupo porque são elas que fornecem identidade e um papel social aos indivíduos (ANZIEU, 1994).

Anzieu (1984) chama de ilusão grupal o estado psíquico dos grupos que promove a autodefesa do grupo contra qualquer forma de ataque externo. A ilusão responde a um desejo de segurança, de preservação do grupo.

Todo grupo cria um afeto de grupo (PAGÈS, 1968). Cada indivíduo compartilha com seus semelhantes suas experiências afetivas. A troca de experiências afetivas confere ao grupo uma identidade afetiva compartilhada. Com isto, estabelece-se um laço original. Esse laço original, segundo Pagès (1968) é uma dependência afetiva arcaica. Todo grupo vive um sentimento de euforia coletiva (ANZIEU, 1984). Este sentimento se renova a cada entrada de novo integrante no grupo. Esta prática visa à 
A MANIPULAÇÃO DA VIDA AFETIVA DOS GRUPOS:

autoafirmação do grupo. É uma forma de dizer, "estamos bem juntos", "somos um bom grupo". No grupo, os indivíduos adquirem uma noção diferente de poder, de potência, que os fazem aderir aos instintos. As afetividades dos indivíduos são potencializadas e a capacidade reflexivas e intelectuais diminuídas (LE BON, 1991).

Segundo Freud (1991), nos grupos, as emoções dos indivíduos são excitadas até um grau que na individualidade raramente ocorre. Essas emoções são agradáveis e subsumem os indivíduos a irrestritas paixões, que fortalecem o mecanismo de vinculação com o coletivo, fazendo-os perder os limites da individualidade. A supressão das potencialidades individuais é transferida para o coletivo. O indivíduo "abre mão" do seu ser particular para se transformar em entidade coletiva. Outra característica é que quanto maior for o número de pessoas em que a mesma emoção possa ser simultaneamente observada, mais intensamente cresce esta compulsão automática. $\mathrm{O}$ indivíduo perde o seu poder de crítica e deixa-se deslizar para a mesma emoção. A impressionabilidade é outra característica que um grupo exerce no indivíduo isolado. Há a percepção de que o grupo tem o poder maior do que ele mesmo tem.

Com o surgimento de um grupo, nascem sentimentos ambivalentes e complexos em relação a si mesmo e aos outros. No grupo verifica-se a presença de sentimentos de como amor e ódio, de forma que a questão básica não é "o que vamos fazer juntos", e sim "quem são os amados e os rejeitados, as pessoas conformes e os traidores em potencial". Tais sentimentos estão presentes em todos os grupos e podem influenciar o seu funcionamento.

A interação entre os indivíduos implica na forma como as relações são capazes de criar, disseminar e desfazer os sentimentos que permeiam o "ambiente" individual e grupal. Os sentimentos são compartilhados a todo momento por todos os membros de um grupo manifestam-se em todos os níveis da vida do grupo; os sentimentos individuais estão em relação com os sentimentos coletivos (PAGÈS, 1976, p. 265).

Freud (1991) afirma que o sentimento de unidade e colaboração deve ser permanente, o que induz a aceitação das lideranças com maior facilidade. Geralmente, a figura do líder exerce grande fascínio sobre os liderados; o que está presente são as projeções como fator primeiro na constituição do imaginário da liderança ideal. O papel do líder é antes concebido na formulação idealizada do grupo, no plano inconsciente que se deu a partir da vivência dos indivíduos com sua história com o poder (LAPIERRE, 1995). O estilo de liderança instituído no grupo (KERNBERG, 2000, p. 147) é essencial para o funcionamento do grupo, pois os líderes facilitam no estabelecimento das relações imaginárias com a realidade e com os indivíduos que o compõem.

As atribuições do líder, independente do grupo em que ele se manifesta, são vistas como um instrumento capaz de propiciar aos grupos 
A MANIPULAÇÃO DA VIDA AFETIVA DOS GRUPOS:

a coordenação e a utilização dos recursos disponíveis para atingir os objetivos almejados. A figura do líder é antes imaginada no seu estado ideal na cabeça de cada membro do grupo. A capacidade do líder em atender às expectativas imaginárias dos liderados é determinante para a sua aceitação dentro da coletividade. Grande parte da manifestação de apoio e, consequentemente, de legitimidade, ocorre devido a isso. Entre as expectativas esperadas, segundo Lapierre (1995), destacam-se (i) os interesses e objetivos particulares que os indivíduos pretendam alcançar através do grupo; (ii) $\mathrm{O}$ reconhecimento pessoal, através da valorização das suas capacidades, por parte do grupo ou da organização em que estão inseridos; (iii) As recompensas sociais e materiais como forma de reconhecimento pelos esforços despendidos em nome do grupo; (iv) Reconhecimento como integrantes legítimos do grupo e a valorização e atendimento de seus desejos através dos objetivos coletivos.

A liderança é fundamental para criar estabilidade na vida afetiva dos grupos. Assim, as organizações investem nas lideranças como recurso para realizar seus objetivos e metas.

\section{Metodologia}

Este é um estudo de caso descrito qualitativo. O nível de análise é organizacional e a unidade de análise o grupo de funcionários que trabalham nos setores da loja de departamentos. A perspectiva temporal é seccional, pois é feita a análise de um registro fílmico realizado na Organização $\mathrm{R}$, apesar de terem sido realizados dois registros fílmicos. A escolha por um deles, considerado o mais completo, deve-se ao fato que no outro registro fílmico e nas outras duas observações participantes (que não foram registrados com filmagens) não houveram mudanças significativas no conteúdo e na forma em relação a dinâmica de grupo (reunião diária) gravada e apresentada integralmente nesta pesquisa. Os registros foram realizados com a autorização da organização e dos funcionários participantes. Eles sabiam previamente que se tratava de uma pesquisa científica e que as imagens não seriam expostas para outras pessoas além dos pesquisadores ou veiculadas em qualquer tipo de mídia. Os nomes das pessoas são fictícios, assim como da própria organização. Participaram da dinâmica (reunião diária) gravada 25 funcionários.

Nas quatro situações específicas em que a pesquisadora esteve na organização, sua presença pode ser percebida pelas pessoas que estavam participando da dinâmica. Na observação participante, o observador não é mero expectador do fenômeno estudado, ele exerce certa influência no fenômeno. A observação participante é indicada para estudos com observações de grupos e outras formas de coletivos. Nestes casos, o observador tem mais condições de compreender os comportamentos, hábitos, atitudes e vínculos que estão presentes. As orientações 
A MANIPULAÇÃO DA VIDA AFETIVA DOS GRUPOS:

metodológicas para realização da observação participante estão fundamentadas nas obras de Creswell (2007), Richardson (1999) e Selttiz, Wrightsman, Cook (1987).

Os registros fílmicos foram realizados porque é a forma mais adequada de registrar conjuntos de ações humanas complexas e de difícil entendimento. Ele é utilizado quando vários outros eventos não sonoros são considerados fundamentais para compreender o fenômeno analisado. Segundo Loizos (2000), existem três razões principais para a utilização de registros fílmicos. Em primeiro lugar, a imagem, acompanhada ou não de som, oferece um registro restrito e confiável de ações temporais e de acontecimentos reais, concretos e materiais. A segunda razão é a de que, embora a pesquisa social esteja a serviço de complexas questões teóricas e abstratas, ela pode empregar, como dados primários, informações visuais que não necessitam ser nem em forma de palavras escritas, nem em forma de números. A terceira razão está ligada a crescente influência dos meios de comunicação, cujos resultados, dependem diretamente de elementos visuais.

Conforme lembram Bauer e Gaskell (2000), embora os registros fílmicos sejam simplificações em escalas secundárias e reduzidas da realidade tridimensional que lhes deu origem (portanto, tratados como bidimensionais), não estão isentos de problemas ou manipulações, uma vez que não são nada mais que representações, ou traços de um complexo maior de ações passadas. Os mesmos autores afirmam que no emprego desta espécie de fonte de dados, o pesquisador deverá ater-se a uma série de tarefas distintas, tais como: exame sistemático do corpus de pesquisa; criação de um sistema de anotações em que esteja claro porque certas ações ou sequência delas devem ser categorizadas de modo específico; promoção de um processamento analítico da informação colhida. Os pesquisadores seguiram as orientações apresentadas. O registro fílmico foi fundamental porque possibilitou o registro de manifestações de sentimentos e emoções que somente a gravação de voz não possibilitaria registrar. As interpretações dos aspectos visuais são desta forma de extrema importância para conhecer mais a fundo os elementos que compõem a dinâmica dos grupos e seus imaginários que não poderiam ser registrados sem a dimensão visual. A tabulação das imagens e sons do registro fílmico apresentado segue o modelo proposto por Rose (2000).

A Organização Estudada surgiu em 1912 como um novo negócio de uma indústria fabril instalada no Rio Grande do Sul. A indústria da área de vestuário criou pontos de vendas a partir de 1922 para comercializar seus produtos e, a partir de 1940, ampliou seus negócios comerciais tornando-se uma loja de departamentos. Em 1965, com o crescimento e evolução dos negócios, a empresa abre o seu capital e torna-se uma S.A, passando, anos mais tarde (1967), a comercializar suas ações na Bolsa de Valores. Nos anos 1990, a empresa reestrutura-se e passa a operar como 
A MANIPULAÇÃO DA VIDA AFETIVA DOS GRUPOS:

loja especializada de moda, o que possibilitou o aumento do lucro e a consequente expansão para outros estados. Seu posicionamento de mercado é o de oferecer produtos de qualidade a preços competitivos. Entre os anos de 1990 até 1998, a organização passa de 8 para 21 lojas de departamentos, atuando em diversos estados no Brasil.

A partir de 1998, a Organização R passa a ser controlada por uma das maiores lojas de departamentos dos Estados Unidos. Em 2005, chega ao número de 64 unidades e abre totalmente seu capital com 100\% de ações em circulação, possibilitando assim estender suas operações para o Norte e o Nordeste do país, chegando a 95 unidades instaladas. Em 2008, figura entre as três maiores redes de departamentos de vestuário do Brasil com 110 unidades instaladas. Atualmente, conta com cerca de 11.000 funcionários, nominados de colaboradores pela direção da Organização R. A loja em que foi feita a pesquisa é a unidade S.J. (sigla também fictícia). Essa unidade conta com 60 funcionários, na sua grande maioria recémcontratados, que receberam e recebem treinamentos intensos.

A Organização $R$ desenvolveu um novo processo interno para melhorar a comunicação nas lojas. Cada loja passa a ter alguns funcionários, que são escolhidos por suas gerencias, que recebem treinamentos para criar situações dinâmicas para divulgar os resultados obtidos (por setor, por funcionário, por unidade, etc.) e comunicar novas metas de vendas e de satisfação no atendimento aos clientes. Esses funcionários escolhidos, que fazem parte da equipe de comunicação, recebem treinamentos específicos para aplicar dinâmicas lúdicas (sobretudo cantorias de músicas, danças e brincadeiras típicas da infância) para facilitar o processo de comunicação das metas realizadas e a serem atingidas. As reuniões são realizadas diariamente, nos dois turnos (manhã e tarde), a cada início de atividades, após a troca de turnos. São reunidos em torno de 25 funcionários em um grande círculo e ali começam as comunicações dentro de algumas dinâmicas lúdicas.

\section{Análise dos Dados}

A análise dos dados será realizada com a apresentação da parte empírica e posterior a ela a apresentação das análises relacionadas com os elementos teóricos apresentados na fundamentação teórica.

\section{Situação 1}

O funcionário T. do grupo de comunicação faz a divulgação dos resultados negativos do dia anterior enquanto o gerente e as subgerentes da loja se junta aos demais para a realização do ritual. A expressão dos funcionários continua séria e muitos olham para o chão enquanto os resultados negativos do dia anterior estão sendo divulgados, nesse momento alguns deles iniciam o movimento de 
A MANIPULAÇÃO DA VIDA AFETIVA DOS GRUPOS:

pêndulo, apoiando-se hora sobre a perna esquerda, hora sobre a perna direita.

Gerente da loja: Bateu [a meta]? Põem [os resultados]. Bateu?

Funcionário L: [A meta do setor] Feminino era $X$ [Reais], realizado $Y$ [Reais]. Masculino era $X$, realizado $Y$. Infantil $X$, realizado $Y$. Calçados $X$, realizado $Y$. Lingerie $X$, realizado $Y$. Beleza $X$, realizado $Y$. Acessórios $X$, realizado $Y$. Zero + 8 , [qual que é a meta que precisava ser atingida]?

Todos os funcionários: 17 !

Ao término dos números, o Funcionário T. gesticula abatinando os demais funcionários sobre as metas de cartão de crédito (fazer novos cartões) e financiamentos de compras. O Funcionário T. do grupo de comunicação bastante sorridente promove uma espécie de brincadeira de adivinhação dos números e propões que quem acertar o valor escolhe algum outro funcionário para pagar um "mico". Todos riem.

Funcionário T: Bateram a meta ontem?

O grupo resiste em responder, junta as mãos em sinal de apreensão, olha para baixo.

Funcionário L: Não. Realizado 14,62\%. Faltou um pouquinho, um pouquinho. É, a meta de cartão, alguém sabe qual é a meta diariamente?

Funcionária Q: Setenta e poucos!

Funcionário R: 50 (risos).

Funcionário L: Alguém sabe o realizado ontem?

Funcionária C: 122 (risos)

Funcionário T: Eu falei que quem acertasse [o resultado, ia] escolher alguém pra pagar o mico. (risos). É, pêra aí! Escolhe alguém pra pagar o mico Funcionária C! Quem você escolhe?

Funcionária C: A Funcionária E.!

A Funcionária C. que acertou o resultado aponta o dedo rindo e escolhe a Funcionária E. para pagar o mico. Todos os demais funcionários riem muito, assoviam e se divertem batendo palmas e entoando em coro o nome da Funcionária E. Nesta hora, a funcionária A. do grupo de comunicação começa a dar pulos batendo palmas e dizendo repetidamente "Conga Conga Conga" 3 . Os demais funcionários aderem ao coro. O Funcionário T. do grupo de comunicação vai correndo ao encontro da funcionária E. e a puxa para o centro do círculo e

\footnotetext{
3 "Conga Conga Conga" é um single da cantora brasileira Gretchen, lançado em 1981. A música chegou ao primeiro lugar nas principais paradas musicais no Brasil. A música tem um ritmo dançante. Para conhecer a música e a letra acesse: http://letras.terra.com.br/gretchen/478443/
} 
A MANIPULAÇÃO DA VIDA AFETIVA DOS GRUPOS:

ambos dançam no meio da roda, demonstrando empolgação. Os demais funcionários continuam a cantar a música sorrindo e mostrando estarem se divertindo.

Os sentimentos gerados pela situação de não cumprimento das metas potencializam as afetividades dos indivíduos diminuindo a capacidade intelectual dos mesmos (LE BON, 1991), fazendo que os trabalhadores não percebam a situação de constrangimento a que são submetidos. Para explorar esta situação de constrangimento, o líder (Funcionário T, do grupo de comunicação), propõe uma dinâmica em que um dos trabalhadores deve "pagar o mico" como forma de contrapartida do grupo pela não realização das metas. A funcionária escolhida tem neste momento a suspensão da sua vontade individual e passa aceitar a dominação do grupo (PAGÈS, 1992).

Por ser considerada uma vontade coletiva, a funcionária "paga o mico", deixando que sua vontade de não participar não predomine. Para ter a sensação de acolhimento e pertencimento social (PAGÈS, 1992; ANZIEU, 1993), a funcionária abre mão de sua vontade individual e acaba cedendo à expectativa do grupo.

Os demais funcionários aceitam a punição por não terem sidos eles os escolhidos e por acreditarem que é justa a "punição". Com isto, os trabalhadores tornam-se os vilões e as vítimas de si mesmos (PAGÈS, 1992). A "punição" é realizada explorando a dança, prática de espetacularização comum na sociedade moderna. Esta prática faz com que um número grande de pessoas compartilhe das mesmas emoções, fazendo com que a compulsão automática (FREUD, 1991) se manifeste no grupo e faça com que a punição passe a ser aceita de forma coletiva.

Situação 2

Após a dança, o funcionário T. do grupo de comunicação solicita a funcionária C. que acertou a questão sobre a meta que escolha outra pessoa para pagar o mico.

Funcionário T: Escolhe alguma outra pessoa Funcionária E!

Funcionária E: Tenho direito [de escolher outra pessoa]?

Funcionário T: Têm! Vamos lá.

Funcionária E: Pra mesma coisa?

Funcionário T: Não pra outra coisa.

Todos os funcionários ficam mais sérios a espera da escolha. 
A MANIPULAÇÃO DA VIDA AFETIVA DOS GRUPOS:

Funcionária E: Então a Funcionária A!

O funcionário $T$. do grupo de comunicação incentiva, faz sinal com a mão chamando a escolhida que exita em vir, fazendo com que ele vá buscá-la para pagar o mico.

Funcionário T: A Funcionária A.! Fica do meu lado.

A funcionária A. do grupo de comunicação faz cara de apreensiva. Muitos funcionários mantêm as mãos a frente do corpo, demonstrando apreensão e ansiedade.

Funcionária E: A Funcionária A. é café com leite!

Funcionário T: Se prepare que o mico vem.

Com a funcionária A. do grupo de comunicação ao seu lado, o funcionário $\mathrm{T}$, também do grupo de comunicação, abre o papel com suas anotações, projeta o corpo para frente e retoma a sabatina dos funcionários questionando sobre $\mathrm{o}$ destaque do encantômetro ${ }^{4}$.

Funcionário T: Vamos lá gente, a meta hoje do encantômetro. Destaque de hoje quem foi?

Silêncio por alguns instantes, que é quebrado por alguns funcionários tentam adivinhar e chutam alguns nomes.

Funcionária G: Eu!

Funcionária H: A Funcionária V!

Funcionário T: Ela teve 199 abordagens!

Funcionária H: Nossa!

Um pequeno silêncio. E o funcionário T. do grupo de comunicação projeta-se um pouco mais para o centro do círculo e faz um gesto brusco com o corpo.

Funcionário T: O Funcionário T! É mentira gente eu nem vim ontem! (risos).

Funcionário T: Legal, quem foi o destaque do encantômetro?

Vários Funcionários juntos: A Funcionária Q!

Funcionário T: Não teve destaque do encantômetro. Bom, palmas para todo mundo!

\footnotetext{
${ }^{4} \mathrm{O}$ "encantômetro" é uma política da Organização $\mathrm{R}$ que tem como objetivo encantar o cliente por meio do atendimento. $O$ encanto é medido por uma série de indicadores objetivos, realizados junto aos clientes. São utilizadas também pesquisas espontâneas respondidas pelos clientes, além de registros em livros especiais que os funcionários preenchem e que relatam a forma eles fizeram para encantar os clientes.
} 
Após ele dizer que não teve destaque no encantômetro, ergue os braços para o alto e convoca aos demais funcionários para que deem uma salva de palmas e gritos para todos e para a filial. Imediatamente ele é acompanhado.

Funcionário T: Destaque da loja, todos nós. Eh!

Para criar um imaginário baseado na aparência de democracia, colaboracionismo e cooperativismo (ENRIQUEZ, 1989), a Funcionária que "pagou o mico" é convidada a escolher outra para uma nova situação. A lógica do grupo funciona com uma lógica baseada na "perversidade solidária". A escolha da Funcionária A. por ela demonstra que todos devem colaborar. A Funcionária A. faz parte do grupo de comunicação, responsável pela realização das reuniões e implementações das dinâmicas. A participação dela reforça a ideia de que um grupo só se efetiva quando todos participam e acreditam no projeto comum (ENRIQUEZ, 1989).

Outro aspecto importante é que a colaboração da funcionária do grupo de comunicação traz a sensação coletiva de compartilhamento das experiências afetivas ocorre porque todos são iguais. A troca de experiências afetivas confere ao grupo uma identidade afetiva compartilhada (PAGÈS, 1982). Uma nova situação é apresentada na exposição dos resultados. Apesar de uma das funcionárias ter feito 199 abordagens e ter recebido a manifestação de surpresa positiva de uma das funcionárias, as metas que a organização define é sempre maior que a capacidade de realização individual de cada funcionária. Esta prática tem como objetivo reprimir o potencial individual para que prevaleça sempre a potência coletiva (FREUD, 1991).

Percebe-se também a manifestação do reconhecimento do desejo e o desejo de reconhecimento (identificação) quando os funcionários demonstram querer ter atingido as metas (ENRIQUEZ, 1997). A organização procura manipular estes sentimentos na medida em que procuram gerir objetivamente as metas. Há neste processo uma "gestão" das expectativas e das frustrações.

\section{Situação 3}

Na sequência, com uma expressão mais séria o Funcionário $\mathrm{T}$ inicia a divulgação das metas do dia. Todos os funcionários retomam o papel de ouvintes e a funcionária A. do grupo de comunicação se mostra empolgada com a fala do funcionário T. do grupo de comunicação.

Funcionário T:Vamos lá. A meta de hoje é? Alguém chuta?

Funcionária Q: Eu acho que é Y [Reais]!

Funcionário L.: Errooou! É X [Reais]. A meta por setor hoje é X para o feminino, X 
A MANIPULAÇÃO DA VIDA AFETIVA DOS GRUPOS:

para o masculino, infantil $X$, calçados $X$, lingerie $X$, beleza $X$, acessórios $X$.

Volta o movimento de pêndulo dos funcionários que projetam o olhar para outros locais ou para o chão, de forma dispersiva. Eles só retornam o olhar uns para os outros e para o funcionário T. quando este projetando o corpo para frente e os questiona.

Funcionário T: Vamos realizar!?

Todos respondem em voz alta.

Todos os funcionários: Vamos!!!

Funcionário T: É isso aí! Olha o mar.

Todos os funcionários colocam os braços estendidos para frente e balançam respondendo.

Todos os funcionários: Chuá, chuá, chuá, chuá!

Dando pulos e entoando o "Conga La Conga", o funcionário T. do grupo de comunicação vai ao centro do circulo e puxa a Funcionária $K$, os demais funcionários riem e também cantam a música batendo palmas para que a Funcionária K, que cerra os lábios em sinal de vergonha, dance. A funcionária A. do grupo de comunicação se mostra bastante empolgada e pula bastante durante a ação.

Esta situação demonstra claramente o papel da liderança no grupo. O primeiro papel do líder é facilitar o estabelecimento das relações imaginárias com a realidade (LAPIERRE, 1995). Ele é responsável por estabelecer processos de mediação objetivos e intersubjetivos entre os interesses da organização e os funcionários. A capacidade de criar condições "reais" de realização dos objetivos é outra tarefa da liderança. Para incrementar o sentimento de que o "grupo pode", imediatamente o líder apela para a música como recurso de criar emoções nos integrantes da equipe fazendo-os que se unam no projeto comum estabelecido e na identificação como forma de união. Esta prática da música tornou-se um costume, capaz de determinar as relações entre os trabalhadores, conferindo identidade coletiva ao grupo (ANZIEU, 1993).

A estratégia de adivinhação das novas metas tem como função fazer os trabalhadores acreditarem que é um projeto coletivo. Para isto, o líder é responsável por embutir no coletivo um desejo que na realidade atende os interesses da organização (ANZIEU, 1993). O líder tem como atribuição, portanto, embutir um desejo individual como sendo desejo coletivo e faz a partir de uma dinâmica em que o discurso dominante da organização passa a ser o discurso de todos os trabalhadores. 
A MANIPULAÇÃO DA VIDA AFETIVA DOS GRUPOS:

Situação 4

Depois de um tempo, novamente sério o funcionário $\mathrm{T}$. do grupo de comunicação volta ao seu lugar no círculo.

Funcionário T: Então vamos lá!

Quando é interrompido pelo gerente de loja.

Gerente loja: É! Isso vocês copiaram de algum lugar.

O funcionário T. do grupo de comunicação acompanhado da Funcionária A e os demais funcionários se mantêm quietos a espera da sequência da fala do funcionário $\mathrm{T}$. do grupo de comunicação. O funcionário $\mathrm{T}$. do grupo de comunicação olha suas anotações.

Funcionário T: Foi no treinamento. É pessoal! Vamos cantar o grito, mas antes vamos fazer uma brincadeirinha. "Telefone sem fio ${ }^{5 "}$. Eu vou fazer a frase e se a Funcionária A. acertar, palmas para ela. E se ela errar vai pagar o mico aqui na frente. Aqui no meio, é o mico! Beleza então? Eu vou começa com a frase.

A funcionária A. do grupo de comunicação expressa um sorriso sem graça e faz menção a algum paço de dança.

A maioria dos funcionários: Ah! Ih!

Funcionária A: Ah! Não vale.

O funcionário T. do grupo de comunicação coloca o papel entre seu rosto e da subgerente e cochicha algo para ela. Os demais funcionários começam a fazer barulho e conversar na tentativa de dificultar a tarefa.

Enquanto os funcionários tentam falar a frase passando-a um por um, o funcionário T. pulando e batendo palmas convoca a equipe para que façam mais barulho. Ele pula e canta uma música.

\footnotetext{
5 "A brincadeira do telefone sem fio é uma tradicional brincadeira popular que funciona assim: numa roda de muitas pessoas, quanto mais pessoas mais engraçado ela fica, o primeiro inventa secretamente uma palavra e fala - sem que ninguém mais ouça - nos ouvidos do próximo (à direita ou à esquerda). Assim, o próximo fala para o próximo e assim por diante até chegar ao último. Quando a corrente chegar ao último esse deve falar o que ouviu em voz alta. Geralmente o resultado é desastroso e engraçado, a palavra se deforma ao passar de pessoa para pessoa e geralmente chega totalmente diferente no destino. É possível competir dois grupos para ver qual grupo chega com a palavra mais fielmente ao destino. Costuma-se também fazer referência a essa brincadeira em qualquer situação que possa haver falhas de comunicação num ambiente que depende de um passar a informação para o outro sucessivamente até chegar num destino. Pode-se fazer crítica a alguma hierarquia numa empresa, por exemplo, dizendo que a ordem do chefe passou como um "telefone sem fio" até chegar ao último empregado que a executou de forma totalmente diferente." Disponível em http://pt.wikipedia.org/wiki/Telefone_sem_fio_(brincadeira)
} 
Funcionário T: Vamos fazer barulho! (palmas) Ah! Ah! Organização R de São José.

Todos os funcionários cantando: Vou deixar a Organização R. me levar pra onde ela quiser. Aqui é o meu lugar, na organização R. de São José. Sempre queremos te agradar, pois, a qualquer hora vai estar de volta porque nós vamos te alegar. Vou deixar a organização R me levar pra onde ela quiser. Seguir o coração com alegria e fé. Não tenho hora pra voltar não, pois aqui tem disposição de sobra pra com certeza te encantar. $\mathrm{Na}$, na, na. Eu posso sentir a magia, com toda equipe em harmonia, então vou ficar aqui, aproveitar essa loja, dando o melhor de mim, e você se puder nos conheça. Vou deixar a emoção bater, todos os dias em mim. Querer sempre te ver, e conquistar você pra mim sim, não tenho hora pra voltar não, eu ainda tenho disposição de sobra, vou com certeza te encantar. $\mathrm{Na}$, na na. $\mathrm{Eu}$ posso sentir a magia, com toda equipe em harmonia, então vou ficar aqui, aproveitar essa loja, dando o melhor de mim, e você se puder nos conheça. Não, não, não tenho hora pra voltar, sempre vou ter disposição de sobra vou com certeza te encantar. Não, não, não tenho hora pra voltar, eu agradeço a sua história, vou com certeza te encantar. Organização R de São José!

Ao final da cantoria a funcionária A., que também participou da cantoria, diz a suposta frase do "telefone sem fio".

Funcionário T: Vai lá!

Expressão de apreensão entre os funcionários.

Funcionária A: A loja realiza e encanta clientes!

O funcionário T. do grupo de comunicação projeta o corpo para frente e questiona.

Funcionário T: Está certo?

Todos os funcionários gritando: Não!

O funcionário T. do grupo de comunicação de frente a funcionária A. do grupo de comunicação, que tem agora uma expressão desconfiada, faz movimentos corporais que indicam falta de ar de tanto rir.

A subgerente da loja aponta o dedo para os demais funcionários e fala.

Supervisora: Viu como [acontece] o telefone sem fio?! Como nunca chega certo na última pessoa?!

Funcionário T. pergunta para a Subgerente: O que eu te falei?

Subgerente: A loja da Organização R realiza encantamento!

O funcionário $T$. do grupo de comunicação começa a pular na frente da funcionária e gritando. 
A MANIPULAÇÃO DA VIDA AFETIVA DOS GRUPOS:

Funcionário T: Mico! Mico! Mico!

O Funcionário T. coloca a mão no ombro dela e a leva ao centro do círculo.

Funcionário T: O que será que a Funcionária A. vai fazer? O que a Funcionária A. vai fazer?

A própria funcionária A tenta cantar um funk e começa a fazer paços de dança os demais funcionários cantam e batem palmas. $\mathrm{O}$ funcionário mais empolgado com a ação é o Funcionário T. A funcionária A. do grupo de comunicação se mostra desinibida na ação. Na sequência o funcionário T. do grupo de comunicação eleva os braços e grita.

Funcionário T: Olha o mar!.

Todos os funcionários movimentando os braços: Chuá, chuá, chuá, chuá.

Funcionário T: Aêh!!!!!.

A organização procura instituir sua ideologia a partir de músicas e danças. A exploração de dinâmicas lúdicas tem como objetivo facilitar que sentimentos ambivalentes complexos possam ser amenizados nos grupos (FREUD, 1991) e assim possibilitar que a organização possa explorar a vida afetiva do grupo. A ideia que se tem é que a organização fornece condições para que os indivíduos possam realizar seus desejos a partir de condições lúdicas criadas.

A brincadeira infantil é um recurso que faz com que os trabalhadores aceitem os valores que a organização tenta instituir. A dinâmica da brincadeira é feita explorando dois elementos fundamentais. Uma é a de criar condições de dificuldade que simule a realidade da organização. A outra é que a situação simulada se difere da realidade porque o recurso utilizado para dificultar a compreensão da frase no telefone sem fio está associado a uma música que todos conhecem e é utilizada como elemento de agregação entre os trabalhadores. Esta situação mostra que a manipulação da vida afetiva dos grupos ocorre com simulações em que as circunstâncias de adversidades devem ser transformadas em aprendizado. Naturalmente que a Organização R utiliza-se da liderança para mediar estas adversidades em favor dos interesses da organização.

\section{Situação 5}

O gerente faz um gesto assertivo e os funcionários, inclusive o funcionário $\mathrm{T}$, ficam sérios juntando as mãos à frente do corpo na altura do quadril demonstrando nitidamente medo. Alguns retomam o movimento de pêndulo.

Gerente de loja: Só um minutinho! Pessoal, vamos prestar atenção! Hoje é sextafeira; chegou bastante produto. Chegaram três caminhões durante a semana. 
A MANIPULAÇÃO DA VIDA AFETIVA DOS GRUPOS:

Muito produto bom. É pouco movimento nas ruas, pouco movimento no shopping, mas nós precisamos aproveitar toda oportunidade aqui dentro da loja! Então sempre atendimento em primeiro lugar! Se tiver que organizar o setor, vamos largar [esta atividade e dar] prioridade para o cliente. É claro, a gente fala todo dia a mesma coisa, mas é bom estar reforçando. Se o cliente estiver com mercadoria na mão, ofereçam uma sacola, ofereçam o atendimento. É só assim que nós vamos chegar a nossa meta, que hoje é bastante alta X [Reais]. Para o cenário que nós estamos vivendo é bastante alto, eu vejo o calçadão ali [fora] que tem bastante fluxo, mas nas lojas muito pouco fluxo. Conversando com a gerente das lojas M. e da P. eles também estão sentindo este momento, que é um momento de crise. O que eles estão fazendo é o atendimento personalizado, contato com cliente, o cliente entrou na porta já tão atendendo. Nós temos que fazer, porque a nossa cultura é essa. Se a nossa cultura é encantamento. Temos que praticar o encantamento. E essa é a mensagem da sexta-feira e amanhã é um dia que promete muito! Início do mês, hoje é praticamente o quinto dia útil pra muitas pessoas que recebem. Então acabam fazendo as compras e vindo até o shopping pra ver o que tem de novidade. No shopping também as lojas tão com bastante (sem palavras). As vitrines [estão] muito bonitas, estão chamando a atenção do público. É isso aí gente!

Muitos funcionários ouvem de cabeça baixa e olham para o chão. Com uma palma ele finaliza o discurso.

Esta situação mostra a subordinação dos trabalhadores com as chefias das organizações (ANZIEU, 1993). O gerente exerce a função de produzir e reproduzir a ideologia capaz de estabelecer controle sobre os indivíduos. Mesmo que não esteja presente diretamente na sua fala, ele faz a mediação das recompensas objetivas e intersubjetivas entre a organização e seus trabalhadores (PAGÈS, 1982). Nesta situação é possível perceber que o espetáculo é ideologia, porque apresenta e manifesta todo o sistema ideológico na sua plenitude (DEBORD, 2002). Os trabalhadores são levados a sujeição ao controle da organização, ao empobrecimento da sua vida afetiva e à negação da sua vida real por inserção em situações de ilusões criadas artificialmente.

Situação 6 - Inclusão do Grupo

Subgerente: Gente! Vocês perceberam algo de diferente hoje?

A subgerente questiona os demais funcionários se perceberam algo diferente. Em coro, os funcionários sérios respondem.

Todos os funcionários: Sim.

Subgerente: O quê?

Todos os funcionários: Convidado 
A MANIPULAÇÃO DA VIDA AFETIVA DOS GRUPOS:

O funcionário T., que se mostra empolgado e começa a pular, a bater palmas, e cantar "Conga Conga Conga", ele vai em direção da pesquisadora que realizada a filmagem e a puxa para centro do círculo para dançar. $O$ vídeo é interrompido. A pesquisadora vai ao centro e dança a música.

O grupo cria uma ilusão grupal e promove a entrada da pesquisadora no seu ritual de dança como uma forma de se proteger contra ataques externos (ANZIEU, 1993), visto que a pesquisadora até aquele momento é visto como algo externo ao grupo. Com isto, o líder cumpre seu papel de incluir a pesquisadora para evitar que o grupo seja questionado ou mesmo criticado (ANZIEU, 1984). A participação da pesquisadora na dança faz com que o grupo viva um sentimento de euforia, renovando o sentimento de grupo, pois percebe seu potencial de incorporar novas pessoas no seu projeto comum (ZIMERMAN, 1997).

Nesta situação, a atitude do líder faz com que o sentimento que o grupo tenha em relação a ele seja reforçado, pois ele atende as expectativas imaginárias do grupo. Isto faz com que ele seja aceito mais facilmente (FREUD, 1991), pois atende a formação idealizada do grupo (LAPIERRE, 1995).

\section{Considerações Finais}

A Organização R adota práticas de espetacularização para disseminar sua ideologia. Exploram dinâmicas lúdicas como a música, a dança e brincadeiras infantis para fazer com que os indivíduos do grupo possam aceitar as metas e os objetivos definidos pela organização. As dinâmicas lúdicas servem para manipular a vida afetiva do grupo pesquisado a partir da manipulação de emoções e sentimentos ambivalentes, inerentes a qualquer grupo.

O papel da liderança neste processo é fundamental, pois é por meio dele que o processo de identificação se torna efetivo nos grupos. A condução do processo comunicativo na organização, através das reuniões diárias, institui uma prática ritualística e habitual, importante para a formação dos vínculos sociais entre os trabalhadores da organização.

O grupo cria, por meio da liderança orientada pela ideologia da organização, condições de "gerir" suas emoções e sentimentos ambivalentes baseado na mediação entre o desejo de reconhecimento e o reconhecimento do desejo. Apesar disto, não é possível afirmar que exista como controlar a vida afetiva dos grupos, apesar de ser possível manipular aspectos objetivos (criar novas dinâmicas, introduzir práticas lúdicas como músicas, danças e brincadeiras) em favor dos interesses da organização. 
A MANIPULAÇÃO DA VIDA AFETIVA DOS GRUPOS:

As emoções e sentimentos manifestos são ambivalentes. Mas é exatamente por esta ambivalência que as relações de identificação vão se formando. O desejo de reconhecimento e o reconhecimento do desejo (ENRIQUEZ, 2007) só se efetiva na medida em que os indivíduos abrem mão dos seus desejos individuais em prol de um projeto comum, em que todos passam a lutar para que ele se realize.

Ocorrem processos de vínculos sociais pela ilusão de que todos são iguais. Por participarem das mesmas "brincadeiras", cantarem as mesmas músicas, se submeterem aos mesmos "micos", estabelece-se uma ilusão de igualdade, fazendo com que o grupo torne sua imagem de unidade potencialmente maior que as percepções individuais em relação aos constrangimentos em que os trabalhadores são submetidos. Um sentimento de solidariedade coletiva mascara as perversidades individuais, os medos, os constrangimentos e a inveja, quase sempre manifestos nos gestos e nos movimentos do corpo.

A Organização $R$ investe formalmente na criação de um grupo de comunicação em que seus representantes são vistos como pares pela maioria dos funcionários. Estes são treinados formalmente e se tornam os responsáveis por coordenar ações que criam situações aptas a manipulação da vida afetiva dos grupos. A reunião diária que ocorre com os trabalhadores é realizada com atividades (música, dança e brincadeiras) que despertam sentimentos primitivos, arcaicos. $\mathrm{O}$ potencial de identificação é ampliado na medida em que os indivíduos compartilham sentimentos e emoções em conjunto, mesmos que esses sejam ambivalentes.

A organização $\mathrm{R}$ procura realizar seus objetivos e metas explorando a espetacularização para a disseminação ideológica. Usa das lideranças para ampliar o seu domínio sobre os aspectos subjetivos dos trabalhadores. Com isto, investe na vida afetiva dos grupos para poder ampliar seu controle e conseguir realizar seus objetivos.

\section{Referências}

AMADO, G.; GUITTIT, A. La dinamique des communications dans les groups. Paris, Armand Colin, 1975.

ANSART, P. La géstion des passions politiques. In: L'age d'homme. Lausanne, 1993.

ANZIEU, D. Le groupe et l'imaginaire. Paris, Dunod, 1984.

BAUER, M. W.; GASKELL, G. (Orgs). Pesquisa Qualitativa, Contexto, Imagem e Som: um manual prático. Petrópolis: Vozes, 2000.

CASTORÍADIS, C. The imaginary institution of society. Massachusettes: The MIT Press Cambridge, 1975. 
CRESWELL, J. Projeto de pesquisa: métodos qualitativo, quantitativo e misto. 2 ed. Porto Alegre: Bookman, 2007.

DEJOURS, C. A banalização da injustiça social. São Paulo: Editora da FGV, 2000.

DEBORD, G. The society of spectacle. [1967]. Canberra, Hobgoblin Press, 2002.

ENRIQUEZ, E. Structures d'organisation et controle social. Connexions. Ramonville: Erès (41), 1982.

ENRIQUEZ, E. De la horde à 1'Etat. Paris: Gallimard, 1983.

ENRIQUEZ, E. L'individu pris au piège de la structure estrategique. Connexions. Toulouse: Erès (54):145-61, 1989.

ENRIQUEZ, E. L'organization en analyse. Paris: PUF, 1992.

FARIA, J. H. de. Análise crítica das teorias e práticas organizacionais. São Paulo: Atlas, 2007.

FARIA, J. H. de; MENEGHETTI, F. K. (2007). O sequestro da subjetividade. In. Faria, J. H. de. Análise crítica das teorias e práticas organizacionais. São Paulo: Atlas, 2007.

FREUD, S. Psychologie des foules et analyse du moi. [1921]. In: Essais de psychanalyse. Paris, Payot, 1991.

KAËS, R. Processus et fonctions de l'idéologie das les groupes. Perspectives Psychiatriques. France, Sèves Cedex, v. 33, p. 27-48, 1971.

KERNBERG, O. F. Ideologia, conflito e liderança em grupos e organizações. Porto Alegre: Artmed, 2000.

LAPIERRE, L. (orgs.). Imaginário e liderança. São Paulo: Atlas, 1995.

LE BON, G. Psychologie des foules. 4 ed. Paris: PUF, 1991.

MOTTA, F. C. P.; FREITAS, M. E. de. Vida psíquica e organização. São Paulo: Editora FGV, 2000.

PAGÈS, M. La vie affective des groupes. Paris: PUF, 1968.

PAGÈS, M. et al. L'emprise de l'organization. 4 Ed. Paris: PUF, 1992.

RICHARDSON, R. Pesquisa social: métodos e técnicas. 3 ed. São Paulo: Atlas, 1999. 
A MANIPULAÇÃO DA VIDA AFETIVA DOS GRUPOS:

ROSE, D. Análise de imagens em movimentos. in: BAUER, M.W.; GASKELL, G. (Orgs). Pesquisa Qualitativa, Contexto, Imagem e Som: um manual prático. Petrópolis: Vozes, 2000, p. 137-155.

SELTTIZ, C.; WRIGHTSMAN, E. COOK. Métodos de pesquisa nas relações sociais. Vol. 1. Delineamentos de pesquisa. São Paulo: EPU, 1987.

ZIMERMAN, D. E. Fundamentos técnicos. In: Zimerman, D. E.; Osório, L. C. Como trabalhamos com grupos. Artes Médicas: Porto Alegre, 1997. 